\title{
Los hijos de Moctezuma: ignorancia y prejuicio en las novelas inglesas de aventura del siglo XIX
}

\author{
Nair María ANAYA FERREIRA \\ Universidad Nacional Autónoma de México
}

Es casi lugar común la noción crítico-teórica de que el uso de la "Otredad" en la literatura desempeña un papel primordial en el proceso de formación y reafirmación de valores y creencias dentro de la sociedad que escribe sobre ese "Otro". Mucho se ha escrito sobre la forma en que los países europeos llevaron a cabo una apropiación económica, cultural e ideológica de las regiones colonizadas mediante, entre otras cosas, el uso de la lengua y de la representación. En un fenómeno que se aplica a casi todos los países colonizados, el colonizador representó al colonizado como una entidad transparente e inmune al cambio, de tal manera que este último quedó fijado como un pueblo sin historia objetiva - o con una historia "reducible"-y por tanto sólo sujeto a las transformaciones que le venían del exterior, precisamente de las estructuras coloniales.

Así, dentro de la literatura colonialista, se da un proceso dialéctico en el que la realidad ficcional - situada en un mundo extraño- es, por definición, algo ajeno a la identidad colectiva de la metrópoli, de tal forma que existe una conciencia definitiva sobre lo "Otro", sobre ese lugar y esas costumbres diferentes, y esto, a su vez, ayuda a la sociedad "receptora" a definirse a sí misma. Al mitificar la cultura ajena, la sociedad receptora se mitifica a sí misma. Este fenómeno se ve reforzado por la publicación, aceptación y canonización de las obras literarias, pues esto recrea y perpetúa ciertas imágenes - tanto del "Uno" como del "Otro"- que llegan a constituir identidades sociales y, en última instancia, dominan percepciones individuales y colectivas tanto de la cultura propia como de la extraña.

Durante el siglo XIX, la novela de aventuras constituyó un medio fundamental para dar rienda suelta al mito que generó y apoyó la ideología del imperialismo inglés, pues articuló tres actitudes importantísimas: la de la ética de la superación, la de la libertad y la noción idealista y paternalista de la obligación moral del imperio británico hacia las razas "inferiores". Estas actitudes se constituyeron, como sugiere Martin Green, en valores hegemónicos (en religión, en comercio y en política, la libertad y la ética se tradujeron, por supues- 
to, en el protestantismo, el capitalismo y las formas republicanas o monarquías constitucionales de gobierno, respectivamente), y la forma en que éstas se manifiestan en las novelas de aventura varía según el país y el periodo histórico escogidos por los autores. ${ }^{1}$ Así, en el caso de México y América Latina, hay dos temas preferidos por los novelistas ingleses: el de la Conquista y el de las interminables revoluciones después de la Independencia, temas que, definitivamente, permiten el desarrollo del joven héroe inglés en un ambiente exótico y propenso a la corrupción.

Aunque la Conquista ya había sido tratada por autores ingleses en los siglos XVII y XVIII, adquirió una nueva dimensión durante el siglo XIX gracias a la famosísima obra de William Hickling Prescott: History of the Conquest of Mexico, publicada en 1843. En este artículo analizaré cómo el libro de Prescott proporcionó las bases históricas para las novelas de aventura situadas en nuestro país y exploraré la forma en que contribuyó así a legitimar el establecimiento de la imagen cultural de los mexicanos como un pueblo derrotado, violento y corrupto.

Es bien sabido que, desde su publicación, History of the Conquest of Mexico fue reconocida como una de las obras más sobresalientes en la literatura histórica. Prescott fue el primero en emplear todos los manuscritos y fuentes impresas sobre el México antiguo y la Conquista que se hallaban disponibles en esa época. Esto le dio a su History un aire de imparcialidad escolástica y científica que legitimó el tremendo prejuicio antiindio que la sostiene. La noción que Prescott tenía de la historia estaba definida por una creencia romántica en el progreso y la providencia, y la representación misma de su historia se caracteriza por criterios y convenciones románticos tales como paisajes sublimes, escenarios pintorescos y una narrativa con cualidades dramáticas.

En History as Romantic Art, David Levin explora cómo Prescott y algunos de sus contemporáneos estadounidenses (Francis Parkman, George Brancroft y John Lothrop Motley) consideraban la historia como una marcha continua del progreso humano y que éste, a su vez, había sido diseñado por una "Providencia" que había establecido y regulado las leyes morales del mundo. ${ }^{2}$ Los avances más significativos en la historia fueron posibles gracias al triunfo de principios "morales" como el Cristianismo, la Democracia y la Libertad, por lo que una nación debía su triunfo a su adhesión a algún principio "progresista" que, en turno, armonizaba con la ley natural. El deber del historiador, por

\footnotetext{
${ }^{1}$ Martin GREEN, Dreams of Adventure, Deeds of Empire. Londres, Routlege and Kegan Paul, 1980, p. 28.

2 Véase David Levin, History as Romantic Art. Stanford, Stanford University Press, 1959.
} 
tanto, era organizar acontecimientos que, al menos en apariencia, estuvieran desconectados y, después de reconocer la continuidad de la historia, identificar y transmitir el "espíritu" del periodo y lugar que estaban describiendo. Para lograr esto, el historiador debía tomar el punto de vista de la nación que representara, en un momento determinado, la ley moral y natural, y que condujera la marcha ascendente de la humanidad. El interés didáctico y literario del historiador era, pues, analizar y asentar los motivos, la ética y los resultados del comportamiento tanto de los agentes "progresistas" como los de los "malvados".

El método ideal para expresar este drama moral consistía en incorporar estos principios en personajes de carne y hueso - en lugar de concentrarse en un concepto abstracto de "nación"- que actuaban como los agentes del "espíritu" de su pueblo. Una caracterización bien lograda era, por tanto, fundamental para mantener el interés dramático; como escribió Prescott: "Above all, keep character \& especially the pervading, dominant character of the hero in view. Omit no act or word of this that can illustrate it. Interest is created out of character. All other interest is not only inferior in kind, but in degree".

Según Levin, Prescott concebía los acontecimientos históricos en términos pictóricos, de tal forma que al delinear el retrato de un personaje, se revelaba el carácter esencial de su sujeto de estudio. Explotaba el uso de "tipos" -representantes ideales de un grupo-, y esto le permitía, por un lado, hacer generalizaciones sobre el "carácter" nacional y, por otro, personalizar a los individuos con objeto de que los lectores pudieran entender con facilidad. Este método le resultaba conveniente, además, por otras dos razones. Cuando una figura histórica poseía las características adecuadas para lograr el efecto moral que Prescott deseaba, éste sólo necesitaba presentarla como un tipo ideal, pues, de hecho, las convenciones de la tradición exótica le permitian identificar el tipo al que "pertenecía" el personaje en turno. En segundo lugar, aun cuando el personaje estuviera completamente idealizado, su historicidad -es decir, el que tuviera un nombre histórico, que sus acciones estuvieran relacionadas con lugares y fechas específicas y que los acontecimientos hubieran ocurrido "realmente"- lo individualizaba a final de cuentas.

Como se puede ver, resulta difícil establecer la frontera entre historia y romance, pero lo que resulta más significativo es que para Prescott no era

${ }^{3}$ Citado por D. LEVIN, op. cit., p. 10. "Sobre todo hay que mantener el carácter, en especial el carácter predominante del héroe en cuestión. No se debe omitir ningún acto o palabra que pueda ilustrarlo. El interés se crea a partir del carácter. Cualquier otro tipo de interés resulta inferior tanto en esencia como en grado". (A no ser que se indique lo contrario todas las traducciones son mías.) 
necesario marcar la división, pues, por lo general, los sujetos que escogía se adaptaban bien a sus intereses históricos y literarios. Veamos cuál era su concepción inicial de la History of the Conquest of Mexico:

In short, the true way of conceiving the subject is, not as a philosophical theme, but as an epic in prose, a romance of chivalry; as romantic and as chivalrous as any which Boiardo or Ariosto ever fabled, - and almost as marvellous; and which, while it combines all the picturesque features of the romantic school, is borne onward on a tide of destiny, like that which broods over the fictions of the Grecian poets; - for surely there is nothing in the compass of Grecian epic or tragic fable, in which the resistless march of destiny is more discernible, than in the sad fortunes of the dynasty of Montezuma, - it is, without doubt, the most poetic subject ever offered to the pen of the historian. Is it, for that reason, the best? At all events, being the most poetic, it must be regarded from this point of view, to be treated with full effect. ${ }^{4}$

Esta noción de la historia nos es útil para explicar tanto las virtudes como los defectos de la obra de Prescott. Por un lado, Prescott encontró en la Conquista de México el tema ideal para su talento individual y para sus intereses como historiador. Las convenciones románticas de su tiempo y sus propias limitaciones artísticas - como, por ejemplo, su falta de capacidad para retratar las complejidades de carácter o para acentuar la precisión en el detalle- exigían un tema grandioso que le permitiera concentrarse en escenas espectaculares o en una dimensión más amplia del carácter "nacional".

En este sentido, History of the Conquest of Mexico puede considerarse como una obra de arte magistral que fundamenta su éxito en una excelente organización del material. Prescott logra mantener el interés, que para él era fundamen-

4 Citado en Lewis HANKE, ed., History of Latin American Civilization Sources and Interpretations. Londres, Methuen, 1969, vol. 1, p. 518. "En breve, la verdadera forma de concebir al sujeto no es como un tema filosófico sino como una epopeya en prosa, un romance de caballería; tan romántico y caballeresco como cualquiera que haya inventado Boiardo o Ariosto, y casi tan maravilloso; y que a la vez que combine todos los aspectos pintorescos de la escuela romántica, avance con la corriente del destino, como la que se cierne sobre las tramas de los poetas griegos; pues, seguramente, no existe nada en el rango de la epopeya griega o de la fábula trágica, en donde la marcha irresistible del destino sea más perceptible, como las tristes fortunas de la dinastía de Montezuma. Éste es, sin duda, el tema más poético que se haya ofrecido a la pluma del historiador. ¿Será, por esta razón, el mejor? De todos modos, por ser el más poético, se debe considerar desde este punto de vista para aprovecharlo en su totalidad". 
tal, por medio de la unión de tema y estructura: para él, las diferencias centrales entre las culturas azteca y española eran diferencias de carácter, liderazgo y religión, y la organización de la obra - que fue planeada como un estudio en contrastes dramáticos- hace resaltar en cada nivel algunos aspectos de estas distinciones. Según Levin, para Prescott la trama de su narrativa, que planeó con todo detalle, debía servir de apoyo para una serie de oposiciones que ahora consideraríamos simplistas: la ruina inevitable de un imperio opulento, pero en esencia bárbaro por sus defectos morales inherentes; el triunfo de la civilización sobre la semicivilización, y del Cristianismo (aunque sus representantes, en este caso, distaran de ser perfectos) sobre el canibalismo; la victoria del "genio", "constancia" y hábil liderazgo de Cortés sobre la "pusilanimidad" y "vacilación" de Moctezuma, y después sobre la devoción noble, si bien salvaje, que Cuahtémoc mostró por una causa perdida. ${ }^{5}$

Sin embargo, lo que también emerge del proyecto de Prescott es precisamente su mayor defecto. El uso de convenciones románticas que determinan los tipos y papeles asignados a los españoles y a los indios lo conduce a una serie de distorsiones históricas y psicológicas, distorsiones que, a su vez, quedan reforzadas por la ausencia de un intento genuino por penetrar y comprender la mentalidad y la sociedad de los aztecas. El hecho de que se concentra en el drama y el color de la superficie, en lugar de realizar un análisis serio, y de que carece de capacidad para articular los complejos motivos históricos y psicológicos de los dos grupos de personajes, esconde una incapacidad aún mayor para alcanzar una interpretación profunda de los acontecimientos, pues los considera en relación con los principios "progresistas" que determinaban su criterio para evaluar a los hombres, a las instituciones y a las naciones, y que definían sus nociones sobre la herencia racial, la democracia e, incluso, el espíritu de un país.

Por consiguiente, en el primer libro la visión general de la cultura azteca tiene por objeto establecer una atmósfera romántica, así como las bases morales que justifican la Conquista. A pesar de lo que Prescott consideraba como la pompa oriental de los aztecas y de sus avances en muchas de las artes sociales y mecánicas, para él los mexicanos eran una raza corrupta cuyos defectos morales - surgidos de un ciego fanatismo religioso y manifestados mediante los sacrificios humanos y el canibalismo- justificaban con creces su conquista. Por tanto, era sólo natural que los españoles (como representantes de la "civilización") fueran los instrumentos de la Providencia y el progreso para la destrucción de este cultura "malévola". La dramatización y el punto de vista narrativo de Prescott ponen de relieve la interacción entre carácter y destino,

${ }^{5}$ D. LEVIN, op. cit., p. 164 
así que Prescott - y en consecuencia sus lectores contemporáneos- se identifica por lo general con Hernán Cortés y los españoles aun cuando para él la avaricia, la intolerancia y el orgullo de éstos también los condenaron a convertirse en un país "retrasado". La unidad narrativa se logra mediante contrastes dramáticos entre los españoles y los indios: en un extremo, Cortés representa la virtud progresista, mientras que en el otro, Cuauhtémoc (Guatemozin) representa la virtud salvaje; el resto de los personajes quedan en medio y se acercan gradualmente al elemento del centro, la corrupción, representada por los sacerdotes aztecas y los españoles más avariciosos y arteros. De este modo, en su presentación del enfrentamiento, Prescott puede mantener cierta distancia narrativa y dramática.

Siguiendo de cerca la cronología histórica, Prescott se concentra en el resoluto liderazgo de Cortés, cuyas habilidades políticas y orientación religiosa le ayudan a capitalizar sobre la débil base "moral" del imperio azteca. ${ }^{6} \mathrm{Su}$ sabiduría y determinación contrastan con el miedo, renuencia y debilidad de Moctezuma, quien, según Prescott, personifica la corrupción y decadencia de su pueblo. Las simpatías del punto de vista narrativo quedan establecidas abiertamente. Al principio, los indios aparecen como salvajes nobles y buenos cuyas virtudes principales son el valor, la resistencia y un fuerte sentido de lealtad tribal, pero con cada ataque español, el salvajismo triunfa sobre su refinamiento. La presentación global se logra a través de una serie de oposiciones y cambios dramáticos en el tono narrativo después de cada acción importante: crueles y feroces en las escenas de batallas, los indios aparecen en su peor forma durante los sacrificios rituales; sin embargo, cuando se lleva a cabo la batalla decisiva y la acción se acerca a su fin, simplemente quedan sentimentalizados como una raza "vencida". La narración se concentra en la debilidad y sufrimiento de éstos y, para las batallas finales, su pasividad es tal que ya no pueden ni resistir, su fiereza se transforma en una patética expresión de impotencia.

Algunos de los conceptos que sirven de fundamento a la versión de Prescott sobre la cultura azteca y la Conquista no eran nuevos. En Madoc, poema épico de Robert Southey, publicado en 1805, existe también una contradicción entre la imagen de los aztecas salvajes buenos y sus horripilantes prácticas rituales, pero lo más interesante es que Southey anticipa, en forma un tanto ahistórica,

"En su capítulo "El Virreinato" (La historia mínima de México. México, El Colegio de México, 1973), la doctora Alejandra Moreno Toscano confirma este punto. Según ella, la figura del conquistador dominó el siglo XVI porque las mejores historias de la Conquista fueron escritas por historiadores de la escuela romántica, quienes veían en él al modelo que combinaba los atributos individuales de acción, fuerza de voluntad y triunfo sobre la adversidad. 
la idea de que la conquista de una nación idólatra está plenamente justificada. En este poema, un príncipe galés, Madoc, abandona su patria, que se encuentra en guerra civil, y llega a América, a Aztlán en concreto, antes de que los aztecas inicien su peregrinar a Tenochtitlan. Como es de esperarse, Madoc se convierte en su líder, detiene sus prácticas salvajes y los convierte al cristianismo. Sólo unos cuantos deciden mantener su antigua fe. Dirigidos por el jefe Yuhidthiton pelean contra el grupo de Madoc y caen derrotados, por lo que tienen que escapar:

So in the land

Madoc was left sole Lord; and far away

Yuhidthiton led forth the Aztecs,

To spread in other lands Mexitli's name, And rear a mightier empire, and set up Again their foul idolatry; till Heaven, Making blind Zeal and bloody Avarice Its ministers of vengeance, sent among them The heroic Spaniard's unrelenting sword.?

Lo que hace única la historia de Prescott es la forma en que en una sola obra monumental captó casi todo el conjunto de creencias y actitudes que caracterizaron la idea que la sociedad "occidental" tenía de sí misma y de los pueblos "no-occidentales". La publicación de History of the Conquest of Mexico en 1843 coincide con un periodo en el que se incrementaba el interés europeo por los paises "exóticos", y el éxito inmediato de la obra de Prescott dio validez a una imagen distorsionada, en esencia, de las civilizaciones americanas. Este punto de vista no puede atribuirse sólo a Prescott, por supuesto, pero lo que sí puede establecerse con claridad es que el concepto que él materializó llegó a adquirir la estatura de un mito que funciona como principio ordenador en un gran número de obras literarias inglesas que tratan no sólo sobre México sino sobre América Latina en general. De hecho, autores como Haggard, Henty, Lawrence e, incluso, Lowry, se basan en la obra de Prescott para su propia mitificación de la realidad mexicana y, al hacerlo, la legitiman.

\footnotetext{
${ }^{7}$ Roberth SoutheY, Madoc. Londres, 1805, 2a. parte, XXVII, p. 449. "Así en la Tierra / Madoc quedó como solo Señor; y lejos / condujo Yuhidthiton a los aztecas, / a difundir el nombre de Mexitli en otras tierras, / y a erigir un imperio más poderoso, y a establecer / de nuevo su inmunda idolatría; hasta que el Cielo, / haciendo del Fervor ciego y de la sanguinaria Avaricia / sus ministros de la venganza, envió a su seno / la espada implacable de los heroicos españoles".
} 
La forma misma de la historia de Prescott — con su énfasis, como ya dije, en lo pintoresco, con sus continuos contrastes entre lo esplendoroso y lo horripilante, entre la civilización y el primitivismo, con sus motivos épicos y exóticos y con sus principios progresistas - permitió que fuera asimilada con facilidad a la novela de aventura, un género muy popular en Inglaterra en la segunda mitad del siglo XIX. Dos ejemplo son By Right of Conquest, or With Cortez in Mexico, de George A. Henty, publicada en 1891, y Montezuma's Daughter, de Rider Haggard, que apareció en 1893. Henty y Haggard son dos de los exponentes más importantes y representativos de este género, que trataba, sobre todo, de pueblos "primitivos", y se concentraba en el papel civilizador del imperio británico y en el carácter emprendedor de los jóvenes ingleses. Como veremos más adelante, las novelas "mexicanas" de estos autores están definidas por las mismas suposiciones culturales que caracterizan al resto de su obra, que se sitúa principalmente en África.

Siguiendo la convención del héroe del género colonial de aventura - un chico de clase media venido a menos a causa de algún accidente del destino llega por azar a tierras extrañas, donde tiene que sobrevivir mediante sus propios recursos físicos y morales-, tanto Henty como Haggard utilizan en sus novelas mexicanas a un joven inglés que llega a costas mexicanas después de un naufragio y participa, del lado de los indígenas, en la lucha contra los españoles. A pesar de que ambos escritores se basan en la historia de Prescott -que recomiendan a sus jóvenes lectores en sus respectivos prefacios-, y por tanto dan a entender que describen con exactitud los acontecimientos que llevaron a la destrucción del imperio azteca, la forma en que cada uno aborda el tema varía considerablemente.

Dentro de los límites de una trama directa y más bien magra, Henty subraya el carácter despótico del reinado azteca y su inhabilidad para gobernar con sabiduría a los otros pueblos indígenas que habían conquistado. Para Henty, como para Prescott, la corrupción de la cultura azteca es lo que explica por qué un pueblo tan bravío y guerrero fue derrotado por un mero puñado de españoles: "Even the bravery of the Spaniards and the advantage of superior arms would not have sufficed to give them the victory, had it not been that Mexico was ripe for disruption..."

Henty contrasta el salvajismo cruel y supersticioso de los aztecas con sus pacíficos vecinos los texcocanos, quienes amaban la naturaleza, mostraban un

${ }^{8}$ George A. HENTY, By Rigth of Conquest or with Cortez in Mexico. Londres, Blackie and Son, 1891 , p. V. "Incluso el valor de los españoles y la ventaja de contar con armas superiores no habrían bastado para darles la victoria, de no ser porque México estaba listo para la disỏlución..." 
gran talento artístico y no practicaban sacrificios humanos hasta que fueron obligados por los aztecas. Esta imagen de los texcocanos le permite a Henty establecer cierto nivel de identificación con algunos de los indígenas, especialmente porque Roger, el héroe, pelea al lado de ellos y se casa con Amenche, la hermana del rey. Henty sigue el ejemplo de Prescott al describir a Cortés como ejemplo de virtud progresista: guapo, sagaz, extraordinariamente valiente y atrevido. En cambio, los príncipes mexicanos aparecen como buenos salvajes que sucumben víctimas de sus propias supersticiones. Su valor se ve desplazado por sus prácticas malévolas e idólatras, a las que Roger se refiere a menudo. En el Gran Templo de Tepeaca, por ejemplo, observa una inmensa pila "composed entirely of human skulls"9 y después del sitio de "Mexico" es testigo del sacrificio de algunos prisioneros españoles:

They were driven along with blows, and when they reached the summit of the temple were seized and thrown one by one upon their backs upon the sacrificial stone, which was convex, so as to give a curve to their bodies. The principal priest then with a sharp stone knife cut through the skin and flesh, between two of the ribs, and plunging his hand into the orifice dragged out the heart, which he presented to the figure of the god. ${ }^{10}$

Después de la derrota final de los aztecas, Roger abandona México con joyas suficientes para vivir en la opulencia el resto de sus días. Vuelve a Inglaterra con Amenche, con quien tiene varios hijos "and to this day many of the first families in Devonshire are proud that there runs in their veins the blood of the Aztec princess"."

Rider Haggard, en cambio, intenta una interpretación mucho más psicológica y sutil de la vida azteca y de la conquista de los españoles. A Haggard le interesaba explorar la necesidad del escritor de identificarse con la forma de pensar de las culturas indígenas sobre las que escribía. Quizás por su amistad con el antropólogo Andrew Lang, Haggard siguió de cerca las corrientes antropológicas de su tiempo. Creía en la noción de la relatividad cultural y, por lo general, le concedía a los pueblos indígenas la posibilidad de tener organi-

${ }^{9}$ Ibid., p. 123

10 Ibid., p. 359. "Fueron llevados a golpes y cuando llegaron a la cima del templo fueron arrojados de espaldas, uno por uno, sobre la piedra de sacrificios, que era convexa para seguir la curvatura de los cuerpos. Después, el sacerdote principal, con un afilado cuchillo de obsidiana, cortó a través de la piel y la carne y, metiendo la mano en el orificio, extrajo el corazón que ofreció a la figura del dios".

"I Ibid., p. 384. "[...] y aún ahora muchas de las primeras familias en Devonshire están orgullosas de que corra en sus venas sangre de la princesa azteca". 
zaciones sociales legítimas e incluso una cultura propia. Sin embargo, en sus obras literarias este punto de vista entra en conflicto muy a menudo con su interés por explotar la cuestión de la "organización" de la naturaleza y por descubrir si existía o no una "Providencia" que ordenara los acontecimientos. Su actitud hacia la historia es similar a la de Prescott, pues Haggard suponia también que sólo las naciones que se adherian a los principios morales "correctos" podían alcanzar la libertad y el progreso.

Esta idea desempeña un papel central en Montezuma's Daughter, en donde emplea ingeniosamente la historia de la Conquista de México para proclamar la grandeza del imperio británico. A petición de la Reina Isabel I, Thomas Wingfield se compronete a escribir las memorias de los veinte años que vivió entre los aztecas. La reciente derrota de la Armada española domina su estado de ánimo, así que la narración tiene un tono patriótico, casi chovinista. Desde el principio, Haggard establece el tono antiespañol y anticatólico que caracterizará el resto de la novela:

Now glory be to God who has given us the victory! It is true, the strength of Spain is shattered, her ships are sunk or fled, the sea has swallowed her soldiers and her sailors by hundreds and thousands, and England breathes again. They came to conquer, to bring us to the torture and the stake to do us free Englishmen as Cortes did by the Indians of Anahuac. Our manhood to the slave bench, our daughters to dishonour, our souls to the loving-kindness of the priest, our wealth to the Emperor and the Pope! God has answered them with his winds, Drake has answered them with his guns. They are gone, and with them the glory of Spain... Consider also the fate of those great people of the land of Anahuac. They did evil that good might come. They sacrificed the lives of thousands to their false gods, that their wealth might increase, and peace and prosperity be theirs throughout the generations. And now the true God has answered them. For wealth He has given them desolation, for peace the sword of the Spaniard, for prosperity the rack and the torment and the day of slavery. For this it was that they did sacrifice, offering their own children on the altars of Huitzel and of Tezcat.

And the Spaniards themselves, who in the name of mercy have wrought cruelties greater than any that were done by the benighted Aztecs, who in the name of Christ daily violate His law to the uttermost extreme, say shall they prosper, shall their evil-doing bring them welfare? I am old and cannot live to see the question answered, though even now it is in the way of answering. Yet I know that their wickedness shall fall upon their own heads, and I seem to see them, the proudest of peoples of the earth, bereft of fame and wealth and honour, a 
starveling remnant happy in nothing save their past. What Drake began at Gravelines God will finish in many another place and time, till at last Spain is of not more account and lies as low as the empire of Montezuma lies today. ${ }^{12}$

Pero así como es dificil que exista una identificación narrativa con los españoles, la posibilidad de que el lector se identifique con los indigenas queda eliminada casi desde el momento en que Wingfield llega nadando a tierras mexicanas, después de un naufragio en el Caribe. Los indígenas creen que Thomas es la encarnación del dios Quetzalcóatl y por tanto debe ser sacrificado. En consecuencia, cualquier descripción más o menos favorable de los adelantos técnicos, artísticos o legales de éstos se ve eclipsada por la crueldad de sus creencias religiosas. Esta ambivalencia es la que sostiene la acción de la novela: en la lucha contra los españoles la simpatía del lector se dirige a los aztecas, pero como siente repulsión por las prácticas sanguinarias de éstos, lo que queda es la identificación emocional, única, con el muchacho inglés. Este conflicto es crucial para comprender el significado total de este libro y de muchas otras novelas "exóticas" y de aventuras.

12 H. Rider Haggard, Montezuma's Daugther. Londres, Longmans, Green and Co., 1894 , pp. 1 y 3 . “'Alabado sea el Señor que nos ha dado la victoria! Es verdad, la fuerza de España ha quedado arruinada, sus barcos están hundidos o han escapado, el mar se ha tragado a cientos y miles de soldados y marineros, e Inglaterra respira de nuevo. Ellos vinieron a conquistarnos, a traer la tortura y la hoguera, para hacer con nosotros, ingleses libres, lo que Cortés hizo con los indios del Anáhuac. ¡Querían llevar nuestra hombría al banco del esclavo, deshonrar a nuestras hijas, entregar nuestras almas a la benevolencia de los sacerdotes y nuestra riqueza al emperador y al papa! Dios les ha respondido con sus vientos, Drake con sus cañones. Se han ido, y con ellos la gloria de España [...] Considerad también el destino de los grandiosos pueblos de la tierra del Anáhuac. Causaron mal para que llegara el bien. Sacrificaron las vidas de miles a sus falsos dioses para que se incrementaran sus riquezas, y la paz y la prosperidad permanecieron a través de las generaciones. Y ahora el Dios verdadero les ha respondido. En lugar de riquezas les ha dado desolación, en lugar de paz, la espada española, en lugar de prosperidad potro de tortura y el tormento y la esclavitud. Para esto hicieron sacrificios y ofrecieron a sus propios hijos en los altares de Huitzel y Tezcat.

"Y los españoles mismos, que en nombre de la misericordia forjaron mayores crueldades que las de los ignorantes aztecas, y que en el nombre de Cristo violan a diario su ley a un grado extremo, decidme ¿prosperarán?, ¿les traerá su maldad bienestar? Estoy viejo y no viviré para ver la respuesta aunque ya está a punto de conocerse. Aun así, sé que su perversidad caerá sobre sus cabezas, y parece que los veo, la nación más orgullosa de la Tierra, privada de fama, riqueza y honor, vestigio famélico sin felicidad, salvo en el pasado. Lo que Drake inició en Gravelines, Dios terminará en muchos otros lugares y ocasiones, hasta que al fin España no valga nada y se encuentre tan abatido como lo está hoy el imperio de Montezuma". 
En el prefacio a Nada the Lily, Haggard comenta que el elemento central en sus novelas es el grip, es decir, la capacidad de atrapar la atención de sus lectores en momentos clave de la narración y de mantenerlos en suspenso. En Montezuma's Daughter logra este efecto al seguir los acontecimientos de la Conquista desde el punto de vista puritano del héroe, quien pasa por todo tipo de incidentes (que para cualquier lector mexicano son por demás trillados): se le confunde con un dios blanco; Marina (sí, Marina) le enseña náhuatl y lo introduce a los "secretos" de la cultura; dos veces está a punto de ser sacrificado pero se salva en el último minuto; es el mejor amigo de los príncipes aztecas Guatemoc y Cuitlahua, a quienes instruye; se casa con una princesa india, precisamente la hija de Montezuma; se convierte en el líder de los indígenas y en el estratega principal en las batallas en las que derrotan a los españoles. No obstante, aunque aparentemente llega a asimilarse por completo a la sociedad azteca, en el fondo nunca se integra y retiene siempre su fe cristiana, su conducta caballerosa y sus innatas virtudes morales puritanas, "cualidades" que en última instancia lo hacen superior a los indígenas.

El hecho de que Haggard coloque a Wingfield del lado de los aztecas da la impresión de que siente cierta simpatía por ellos. Sin embargo, al personificarlos, sigue las nociones antropológicas de su tiempo, que se derivan de teorías como aquélla propuesta por Lamarck de que las características culturales se pueden heredar genéticamente, la teoría de la evolución y la sobrevivencia del más fuerte de Darwin y la teoría de sobrevivencias y del animismo del pensamiento primitivo de Tylor. Haggard compartía la creencia de que los pueblos "primitivos" son esclavos de la costumbre e incapaces de romper con el despotismo de su propia "conciencia colectiva". ${ }^{13}$ La descripción de los héroes aztecas queda inscrita en estos términos. Guatemoc, por ejemplo, es valeroso, guapo, inteligente, pero en última instancia condenado por su idolatría (la semejanza con la tipologia de Prescott es notable); sus características intrínsecas lo distinguen de Thomas y esta diferencia simboliza, a su vez, la disparidad entre la fatídica cultura mexicana y la inglesa.

El tratamiento de Otomie, la hija de Montezuma y esposa de Thomas, es también representativo de la forma en que Haggard combina convenciones literarias románticas e ideas antropológicas de su tiempo para describir el "primitivismo" de los aztecas y retener, al mismo tiempo, la atención del lector, además de que muestra la ambivalencia narrativa que caracteriza esta novela. La primera aparición de Otomie en el relato de Wingfield está envuelta en una atmósfera de irrealidad, pero la misma sensación de lejanía e inverosimilitud

${ }^{13}$ Brian V. STREET, The Savage in Literature. Representations of "Primitive" Society in English Fiction, 1858-1920. Londres, Routledge and Kegan Paul, 1975, p. 6. 
con que la describe anticipa el tipo de relación más bien enajenada que Wingfield tendrá con ella:

[...] Indeed, where is the man who would not have been overcome by her sweetness, her beauty, and that stamp of royal grace which comes with kingly blood and the daily exercise of power? Like the rich wonders of the robe she wore, her very barbarism, of which now I saw but the better side, drew and dazzled my mind's eye, giving her woman's tenderness some new quality, sombre and strange, an eastern richness which is lacking in our well-schooled English women, that at one and the same stroke touched both the imagination and the senses, and through them enthralled the heart.

For Otomie seemed such a women as men dream of but very rarely win, seeing that the world has a few such natures and fewer nurseries where they can be reared. At once pure and passionate, of royal blood and heart, rich natured and most womanly, yet brave as a man and beautiful as the night, with a mind athirst for knowledge and a spirit that no sorrows could avail to quell, ever changing in her outer moods, and yet most faithful and with the honour of a man, such was Otomie, Montezuma's daughter, princess of the Otomie. Was it wonderful then that I found her fair, or when fate gave me her love, that at last I loved her in turn? And yet there was that in her nature which should have held me back had I but known of it, for with all her charm, her beauty and her virtues, at heart she was still a savage, and strive as she would to hide it, at times her blood would master her. ${ }^{14}$

${ }^{14}$ (El subrayado es mío.) H. R. HAGGARD, op. cit., pp. 120-121. “[...] En verdad, ¿dónde está el hombre que no habría sucumbido ante su dulzura, su belleza y ese sello de gracia real que viene con la sangre noble y el ejercicio cotidiano del poder? Como las ricas maravillas de la túnica que portaba, su barbarie, de la que ahora sólo veía yo su mejor cara, atrajo y deslumbró el ojo de mi mente, dándole a su ternura de mujer una nueva cualidad, sombría y extraña, una riqueza oriental de la que carecen nuestras bien educadas mujeres inglesas, y que tocaba con una sola pincelada a la imaginación y a los sentidos y a través de ellos subyugaba el corazón.

"Otomie era el tipo de mujer con que todos los hombres sueñan pero que casi nunca consiguen, ya que el mundo tiene pocas de esa naturaleza y muy pocos semilleros donde se las podría educar. Pura y apasionada, de sangre y corazón reales, ricamente dotada y muy femenina, pero también valiente como un hombre y bella como la noche, con una mente sedienta de conocimiento y un espíritu que ningún sufrimiento podria dominar, siempre cambiante en su talante externo, empero sumamente fiel y con el honor de un hombre. Esa era Otomie, hija de Montezuma y princesa de los otomíes. ¿Fue extraño, entonces, que yo la encontrara bella o que, cuando el destino me dio su amor, la llegara a amar? Y sin embargo, existía algo en su naturaleza que, de haber sabido que existía, me hubiera detenido, pues a pesar de su encanto, su belleza y sus virtudes, en el fondo per- 
Después de su matrimonio y de la caída de Tenochtitlan, Thomas y Otomie viajan a los dominios de ella, la Ciudad de los Pinos. Con el tiempo, Thomas se convierte en cacique, procede a abolir los "espantosos" ritos del sacrificio humano y educa a sus hijos cual verdaderos ingleses. Catorce años después, cuando los españoles atacan y rodean la ciudad, Otomie, quien hasta ese momento había sido esposa leal y sumisa, mujer valiente e inteligente, realiza una serie de sacrificios con los prisioneros de guerra. Thomas, sorprendido y horrorizado, se da cuenta de que, en el fondo, Otomie era una idólatra y salvaje. Mientras tanto, Otomie organiza el suicidio colectivo de todas las mujeres otomíes, quienes se lanzan de la cima de una pirámide con tal de no caer en manos de los españoles. Días más tarde, Otomie se envenena porque Thomas la ha rechazado y porque todos sus hijos han muerto. A pesar de que con el tiempo Wingfield justifica el comportamiento de Otomie por considerar que "it was not Otomie that I saw at the rite of sacrifice, but rather the demon Huitzel whom she had once worshipped, and who had power, therefore, to enter into her body for awhile in place of her own spirit" , también está consciente de que "there was a great gulf between us which widened with the years, the gulf of blood and faith".15

La premisa que sostiene al "abismo de sangre y fe" de Thomas Wingfield puede rastrearse en las teorías sobre la pureza racial que prevalecieron en el siglo XIX - como las propuestas por Robert Knox y J. A. Gobineau- y que destacaban, entre otras cosas, la incompatibilidad social entre razas diferentes. Haggard articuló este conflicto un sinnúmero de veces y, por lo general, lo resolvió causando la muerte de la chica indígena, como en King Solomon's Mines y en Heart of the World. En Montezuma's Daughter, Wingfield llega finalmente a Inglaterra y se casa con la devota novia que lo esperó los veinte años. A diferencia de Henty, Haggard no permite que su protagonista goce de un matrimonio feliz con la princesa india, el suicidio de Otomie sirve para acentuar las diferencias morales innatas de la pareja y refuerza el sentido de violencia que da forma a la novela.

Una gran parte de la fascinación que México ejerció sobre los escritores ingleses de la primera mitad del siglo XX se basa precisamente en la imagen de la crueldad y fanatismo religioso atribuidos a los aztecas combinada con la

maneció siempre una salvaje y por mucho que tratara de esconderlo, en ocasiones su sangre la subyugaba". (El subrayado es mío.)

${ }^{15}$ Ibid., pp. 287 y 309. “[...] No era Otomie la que vi en la ceremonia del sacrificio, sino el demonio Huitzel, al que ella había adorado y que era capaz de apoderarse de su cuerpo y tomar el lugar de su espíritu"; "existía entre nosotros un gran abismo que creció con los años,"el abismo de sangre y fe". 
intolerancia y brutalidad de la España de la Leyenda Negra, y que, reforzada y justificada por teorías raciales y por clasificaciones de "carácter nacional", han perpetuado una imagen de México como un país salvaje y violento por naturaleza. Consideradas dentro de una dimensión histórica más amplia, las obras mexicanas de autores como Lawrence, Greene, Huxley, e incluso Dennis Wheatley - cuya novela Unholy Crusade (1967) describe una conspiración india, dirigida por un rubio novelista escocés que encarna a Quetzalcóatl, para derrocar al odioso gobierno mestizo de México y presenta sacrificios humanos en la pirámide de Chichén Itzá en pleno 1960-, no son ni tan originales ni tan singulares como a veces se les quiere considerar, sino que forman parte de una tradición literario-cultural claramente identificable.

Si la historia de la Conquista y los indios prehispánicos son temas que han atraído a los escritores ingleses por el suspenso y la aventura, la historia del México independiente y moderno, junto con la figura del mestizo, son temas que los intrigan y obsesionan, a la vez que delatan su incapacidad para comprender el complejo proceso social y cultural que siguió a la Conquista y que fue, de hecho, completamente diferente del patrón seguido por los colonizadores ingleses que nunca se "mezclaron" con las poblaciones indígenas. Por esta razón no deben extrañarnos las turbadas representaciones de un Lawrence, un Greene o un Wheatley, que ven a los mexicanos como un pueblo "bastardo", poblado por eternos adolescentes que jamás llegarán a madurar y que son, además, criminales en potencia. Vale la pena observar que los términos que se emplean en inglés (cross-breed, half-breed, half-caste, hybrid, mongrel) se aplican sobre todo a la cruza de animales y siempre tienen un tono despectivo cuando se refieren a las personas. Que los mestizos eran degenerados por naturaleza, como lo demuestra Brian V. Street en The Savage in Literature, era una creencia común en la época victoriana. Esta noción se basaba en la supuesta incompatibilidad, tanto social como física, entre las razas, y en la aceptación de las teorías científicas sobre la herencia, el medio ambiente y las jerarquías raciales. Se consideraba que los "híbridos" o "cruzados" eran inherentemente feos, flojos, cobardes, violentos, crueles, siniestros, malvados y traicioneros, villanos miserables, resultado de las transformaciones nocivas y degradantes -en lo moral, físico e incluso en lo espiritual- de los matrimonios interraciales. ${ }^{16}$

Ya en la obra de Rider Haggard se explora la imagen mítica de un México cruel y violento, no sólo como resultado de su pasado azteca, sino a raíz de la perniciosa mezcla racial que determina el carácter degenerado de la nación

${ }^{16}$ Véase B. V. STREET, op. cit., capítulos cuatro y cinco. 
mexicana. En Heart of the World (1896), don Pedro, el líder de una cuadrilla de bandidos, aparece por primera vez acostado en una hamaca que mece una bella joven india. A pesar de que es más bien bajo de estatura, su apariencia impresiona: "His cheeks were flabby and wrinkled, his mouth was cruel and sensuous; and his dull eyes, which were small, half opened, and protected from the glare of the lamps by spectacles of tinted glass, can best be described as horrible, like those of a snake [...] he bore the stamp of evil on his face". ${ }^{17}$ (Cualquier parecido con las descripciones de Lawrence en su obra mexicana es pura coincidencia.) Don Pedro se encuentra siempre en compañía de "halfbreeds, the refuse of revolutions, villains who had escaped the hand of justice and who lived by robbery and murder", una situación que preocupa profundamente al narrador, el indio aristócrata don Ignatio: "Looking at these outcasts it became clear to us that, if we once fell into their power, we could expect little mercy at their hands, for they would think no more of butchering us in cold blood than does a sportsman of shooting a deer". ${ }^{18}$ Las expectativas literarias pronto se cumplen, ya que don Pedro aparta una recámara oscura para poder asesinar a sus huéspedes. No obstante, don Ignatio y Strickland (el ingeniero inglés que lo acompaña) se salvan gracias a la oportuna información de un sirviente indio y, con verdadera justicia poética, don Pedro muere cuando un templo indio se derrumba encima de él.

En Heart of the World, esta representación de los villanos mestizos no se limita a unos cuantos personajes menores. En lo que quizá sea la primera recreación literaria inglesa de este tipo de conflicto racial en México, Haggard establece no sólo una diferencia clara entre indios y mestizos, sino que además introduce el tema de un renacimiento azteca (eso sí, ahora cristianizado) que después explotarían Lawrence, Wheatley y algunos otros escritores menores (como un tal Walker A. Tompkins, en Ozar the Aztec. Love and Adventure in a Lost City, 1935). En Heart of the World, Haggard presenta a don Ignatio, un indio de sangre pura que está decidido a realizar "the dream of an Indian EmpireChristian, regenerated, and stretching from sea to sea". Para lograrlo, quiere

${ }^{17}$ H. R. HaGgard, Heart of the World. Londres, Logmans, Green and Co., 1894, pp. 1 y 3. "[...] sus mejillas estaban arrugadas y flácidas y su boca era cruel y sensual; sus ojos opacos, que eran pequeños, estaban a medio abrir y estaban protegidos de la luz de las lámparas por espejuelos oscuros, sólo pueden describirse como horribles, similares a los de una víbora [...] él ostentaba el sello de la maldad en su rostro".

${ }^{18}$ Ibid., p. 97. "[...] mestizos, el desecho de revoluciones, villanos que habian escapado de la justicia y que vivían robando y asesinando"; "Sólo de ver a estos parias era obvio que si cayéramos en su poder no podriamos esperar clemencia, pues para ellos asesinarnos a sangre fría sería casi como matar a un venado por deporte". 
eliminar al resto de la población, es decir, "the Spaniards and their bastards, the Spanish Mexicans". ${ }^{19}$

El que Haggard haya elegido a don Ignatio como narrador sirve para destacar las premisas raciales en que se basa la novela, pues ideas tales como la superioridad del hombre blanco, la degeneración de los mestizos y la incapacidad de los "nativos" para gobernarse a sí mismos aparecen - a la vista del lector - no como si fueran nociones impuestas por los europeos, sino como si fueran hechos consumados. Don Ignatio, como variación de la figura del buen salvaje, desempeña un papel muy interesante. Descendiente directo de Guatemoc, don Ignatio es el venerado líder de una comunidad indígena en el sur de la república. Sin embargo, a pesar de sus intentos por establecer un imperio indio, está convencido de que existen diferencias culturales y raciales y manifiesta el punto de vista racista de Haggard. Así, acepta sin cuestionarse la superioridad de su amigo inglés, el ingeniero James Strickland (quien lo acompaña en el viaje al "Corazón del mundo", la ciudad perdida en la selva en donde don Ignatio establecerá su imperio) y condena el matrimonio entre Strickland y la princesa india, de nombre Maya (relación interracial que tampoco llega a consumarse, pues los dos mueren trágicamente). Su sueño de fundar un reino indio pero cristiano y regenerado (o sea, en el que se incorporarían valores europeos) confirma su actitud. Además, a su muerte, don Ignatio deja su fortuna a Jones, otro ingeniero inglés que trabaja en las minas, pues los mexicanos sólo la despilfarrarían. (Jones es quien descubre el manuscrito en el que se relata la historia de don Ignatio, de su fallida expedición a la Ciudad del Corazón y del trágico amor entre Strickland y Maya.)

E1 interés de esta novela reside en el hecho de que Haggard asocia a los mestizos con una sección bastante amplia de la población, los "bastardos hispano-mexicanos", y éstos, en turno, representan la maldad. El punto de vista que Haggard tenía sobre los mexicanos no se limitó a sus novelas. En sus memorias escribe sobre el viaje que realizó a México con objeto de buscar el tesoro de Moctezuma y comenta cómo fue atacado, sin éxito, por una banda de bandidos mexicanos. El recuerdo de este incidente justifica una filípica contra el carácter de los mexicanos que anticipa, una vez más, a las de Lawrence, Greene, Huxley y Waugh algunas décadas más tarde y que incorpora una visión de México bastante común en el siglo XIX:

${ }^{19}$ Ibid., pp. 66 y 30. "[...] el sueño de un imperio indio: cristianizado, regenerado y que se extienda entre los mares"; "[...] a los españoles y sus bastardos, los hispano-mexicanos". 
What a land of bloodshed Mexico has been, is still, in this year of revolution (1891), and some prophetic spirit tempts me to add, shall be! The curse of the bloody Aztec gods seems to rest upon its head. There, from generation to generation blood calls for blood. And yet, it only it were inhabited by some righteous race, what a land it might be with its richness and its beauty! For my part, I believe that it would be well for it if it should pass into the power of the United States. ${ }^{20}$

Las novelas inglesas de aventura escritas en el siglo XIX desempeñaron un papel fundamental en el proceso de mitificación imperialista de la Inglaterra victoriana. Este género ayudó a sostener un concepto de nación como sistema de significación cultural que no siempre correspondió a la realidad histórica ni de los ingleses mismos, ni de los pueblos "exóticos" y "primitivos" que el género describió. En el caso de estos últimos, el hecho de que su "primitivismo" se contrastó con las virtudes progresistas del protagonista inglés canceló sus particularidades culturales, es decir, la historia y la geografía propias de cada país sirven sólo como la utilería de cada novela, pero la trama y las características de los personajes "nativos" son siempre los mismos, de tal forma que, para efectos del desarrollo del joven inglés, lo mismo da que sobreviva en las selvas o desiertos de África, en los mares del sur o en tierras mexicanas. Paradójicamente, y dentro del mismo fenómeno de concebir a la nación como un sistema de significación cultural, el género sirvió para establecer imágenes fijas del "Otro" que han prevalecido a través de las décadas y que, incluso, continúan perpetuando los medios masivos de comunicación, en los que incluyo al cine.

Sin embargo, como lo demuestra Homi K. Bahba en Nation and Narration, el concepto de nación como fuerza simbólica de unificación no es tan fijo, ni tan cerrado como parecería y, a pesar de que es sumamente significativo, es también necesario analizar las ambivalencias y ambigüedades subyacentes, pues:

To encounter the nation as it is written displays a temporality of culture and social consciousness more in tune with the partial, overdetermined

${ }^{20}$ H. R. HAGGARD, The Days of my Life. An Autobiography. Londres, Logmans, 1926, vol. 2, cap. XIV. “¿Qué tierra tan sangrienta ha sido México, lo es todavía en este año de revolución (1891) y, un espíritu profético me induce a agregar, seguirá siéndolo! Parece que la maldición de los sanguinarios aztecas permanece sobre su cabeza. Ahí, generación tras generación, la sangre llama a la sangre. ¡Y sin embargo si sólo la habitara una raza virtuosa y recta, qué gran pais sería, con su riqueza y su belleza! En mi opinión creo que sería bueno que pasara al poder de los Estados Unidos". 
process by which textual meaning is produced through the articulation of difference in language; more in keeping with the problem of closure which plays enigmatically in the discourse of the sign... To study the nation through its narrative address does not merely draw attention to its language and rhetoric; it also attempts to alter the conceptual object itself. If the problematic "closure" of textuality questions the "totalization" of national culture, then its positive value lies in displaying the wide dissemination through which we construct the field of meanings and symbols associated with national life. ${ }^{21}$

${ }^{21}$ Homi K. BHABHA, ed., Nation and Narration. Londres, Routledge, 1990, pp. 2-3. "Acercarse a la nación como está escrita exhibe una temporalidad de la cultura y de la conciencia social que armoniza más con el proceso parcial y sobredeterminado por medio del cual se produce el significado textual mediante la articulación de la diferencia en la lengua; que se adecua más al problema de la clausura que actúa enigmáticamente en el discurso del signo... Estudiar la nación a través de su discurso narrativo no sólo dirige la atención hacia el lenguaje y la retórica de ésta, sino que intenta alterar al objeto conceptual en sí. Si el problemático 'cerco' de la textualidad cuestiona la 'totalización' de la cultura nacional, luego entonces su valor positivo radica en mostrar la extensa diseminación que nos permite construir el campo de significados y símbolos asociados con la vida nacional". 